\title{
Model Researchon Oblique Load Carrying Capacity of Batter Pile Groups
}

\author{
V.Naveen, P.D.Arumairaj, S.Janaki Raman
}

\begin{abstract}
Experimental investigations on model vertical and batter pile group in uniform sands are presented. Mild steel piles in two different medium ofsand are used in this investigation. The tests are conducted on model steel pile installed in medium, and dense sand withL/d ratio is 18.75 and different batter angles of $0^{\circ}, 10^{\circ}, 20^{\circ}$, and $30^{\circ}$. These piles are constructed in sand and subjected to uplift loads of $60^{\circ}$ inclination. It was found that the uplift capacity of vertical and batter piles under inclined pulls increased with increase in inclination of piles.it is also observed it a negative batter pile has greater uplift load than positive batter pile.
\end{abstract}

Keywords:-Oblique load, batter pile, batter angle, sand

\section{INTRODUCTION}

Pile foundations are mostly used to carry the superstructure loads to deeper strata. When the soil is not having enough strength to withstand the load from the super structure, pile foundations are preferred.in the case of uplift loading, the pile capacity mainly depends upon the shaft resistance in axial loading. This mainly suits where cohesion less soil is used. Generally uplift forcesmainly acting on pile foundations like dry docks, tall chimneys, tower foundation submerged platforms, pumping stations and structures below the water table. Overturning moment predominates in pile foundation because of wind effects, wave effects and seismic events. In such structures, the induced overturningmoments are transferred to the piles supporting thestructure in the form of compression in some piles and pullout on others. Batter piles are more capable of resisting lateral forces because of its ability to resist large lateralforces along its length and to convert overturningmovement into compression and tension forces. Swelling of soil surrounding the piles also induced uplift forces on pile. Therefore, it becomes necessary to have knowledge on parameters that affect the uplift capacity of pile and their behaviour is one of the interesting areas in geotechnical engineering.

The usual assumption in design of abatter pile is that the pile is capable of resisting the same axialload as a vertical pile of the same type and size and driven tosame stratum. The type of foundation mostly recommended is a combination of vertical and batter piles. In this paper the behaviour of vertical and batter piles under pull out loads has been investigated.

The works on batter piles is very little as compared to vertical piles. During the last few decades, behaviour of

Revised Manuscript Received on April 12, 2019.

V.Naveen, P.D., PG Student, Geotechnical Engineering, karunya Institute of Technology and Sciences, Coimbatore, Tamil Nadu, India.

Arumairaj,Professor and Head, Civil Engineering, KarunyaInstitute of Technology and Sciences, Coimbatore, Tamil Nadu, India.

S.Janaki Raman, Assistant professor, civil engineering, KarunyaInstitute of Technology and Sciences, Coimbatore, Tamil Nadu, India. batter pile has been studied by several researches using theoretical and laboratory studies. Model tests were performed to determine the effect of the batter angle and load capacity of the pile (Murthy 1965; Meyerhof and Ranjan 1973; Awad and Ayoub 1976; Hanna and Afram 1986; Veeresh 1996; Zhang et al. 1999). The behaviour of batter pile on deflection has been investigated by Kubo (1965) and Awad and Petrasovits (1968) from tests on model piles in sand.

\section{SCOPE OF STUDY}

Laboratory model tests on batter pile group have been carried out in two relative densities of sand under oblique loads. The qualitative and quantitative influence of parameters such as configuration of the pile group, batter angle, and direction of loading on ultimate uplift resistance and difference between vertical and batter pile group are investigated

\section{EXPERIMENTAL SETUP}

Experimental program is carried out on square steel tank of size $1 \mathrm{~m} \times 1 \mathrm{~m} \times 1 \mathrm{~m}$, with sides made of steel $5 \mathrm{~mm}$ thick. The testing tank was kept large enough to avoid the boundary effect. The set up was provided with pulley arrangement. $2 \mathrm{~mm}$ diameter steel rope to be used in the pulley to which loading pan is fixed at the end. The tank was filled with river sand at two relative densities medium $(50 \%)$ and dense $(75 \%)$. The loading angle is $60^{\circ}$. The displacement of pile group was monitored using deformation dial gauge with $0.01 \mathrm{~mm}$ accuracy.

The experimental setup is shown in figure 1

\section{MODEL PILE AND TEST SET-UP}

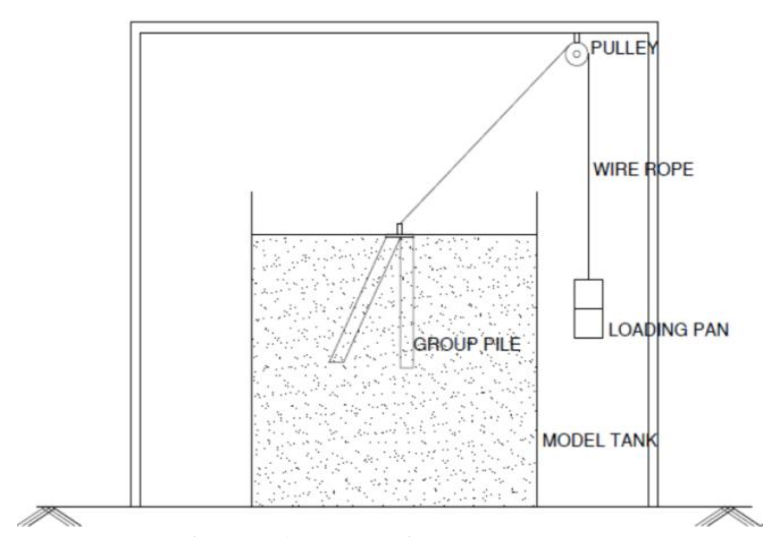

Figure 1: Experimental setup

Published By:

Blue Eyes Intelligence Engineering

\& Sciences Publication 


\section{SOIL USED}

The sand used in the model study was sand taken from the Noyyal river side. Properties of sand are tabulated in table I.

\begin{tabular}{|c|c|}
\hline Properties & Value \\
\hline Specific gravity & 2.64 \\
\hline $\begin{array}{c}\text { Coefficient of } \\
\text { curvature (Cc) }\end{array}$ & 1.10 \\
\hline $\begin{array}{c}\text { Coefficient of } \\
\text { uniformity (Cu) }\end{array}$ & $\mathbf{2 . 2 3}$ \\
\hline $\begin{array}{c}\text { Effective size } \\
\text { (D10)mm }\end{array}$ & $\mathbf{0 . 2 1}$ \\
\hline Soil type & Poorly graded sand \\
\hline $\begin{array}{c}\text { Max dry unit weight } \\
\text { kN/m }\end{array}$ & 18.46 \\
\hline $\begin{array}{c}\text { Min dry unit } \\
\text { weightkN/m }\end{array}$ & 15.2 \\
\hline
\end{tabular}

MODEL PILE

Piles used were mild steel rod with $8 \mathrm{~mm}$ diameter.Total length of pile was kept $150 \mathrm{~mm}$. Mild steel plate of thickness $6 \mathrm{~mm}$ was used for pile cap.Spacing between the piles is $3 \mathrm{~d}$. Hook was attached at the bottom of the pile cap enable application of load.

\begin{tabular}{|c|c|c|}
\hline pile & Batter angle & $\begin{array}{cc}\begin{array}{c}\text { No } \\
\text { test }\end{array} & \text { of } \\
\end{array}$ \\
\hline & $\mathbf{0}^{\circ}$ & 2 \\
\hline & $\begin{array}{l}\mathbf{0}^{\circ},+\mathbf{1 0} \\
0^{\circ},+20^{\circ} \\
0^{\circ},+\mathbf{3 0}^{\circ}\end{array}$ & 6 \\
\hline & $\begin{array}{l}-10^{\circ}, 0^{\circ} \\
-20^{\circ}, 0^{\circ} \\
-30^{\circ}, 0^{\circ}\end{array}$ & 6 \\
\hline 7 & $\begin{array}{c}- \\
10^{\circ}, 0^{\circ}, 0^{\circ},+10^{\circ} \\
- \\
20^{\circ}, 0^{\circ}, 0^{\circ},+20^{\circ} \\
- \\
30^{\circ}, 0^{\circ}, 0^{\circ},+30^{\circ}\end{array}$ & 6 \\
\hline
\end{tabular}

Table 2:Combination of pile

\section{EXPERIMENTAL PROCEDURE}

Pile groupwas placed at the middle as shown in figure 1. Load hanger was attached to the hook provided at the top of pile cap to apply load. Two Dialgaugeswere kept in position to measurethedisplacement.Load increment was done till deflection reaches its limiting value.

No Total numbers of 20 tests were performed on piles in sand 3 set on each on batter angle $\left(0^{\circ}, 10^{\circ}, 20^{\circ}\right.$ and $\left.30^{\circ}\right)$ and 2 vertical pile groups, to study theeffect of load carrying capacity ofbatter pile group. In present study variable werebatter angle and number of piles and rest of otherexperimental condition were kept constant. Eachreading was carefully observed and recorded loaddeflectioncurve have been plotted to study the deflection behaviour of each pile group.

\section{RESULT AND DISCUSSION}

The basic observations from the tests were applied oblique loads and corresponding displacementand also plotted graph for each pile groups. Typical diagrams of load vs. displacement in mediumdense and dense sand. Note: $\mathrm{B}=$ batter pile, $\mathrm{V}=$ vertical pile

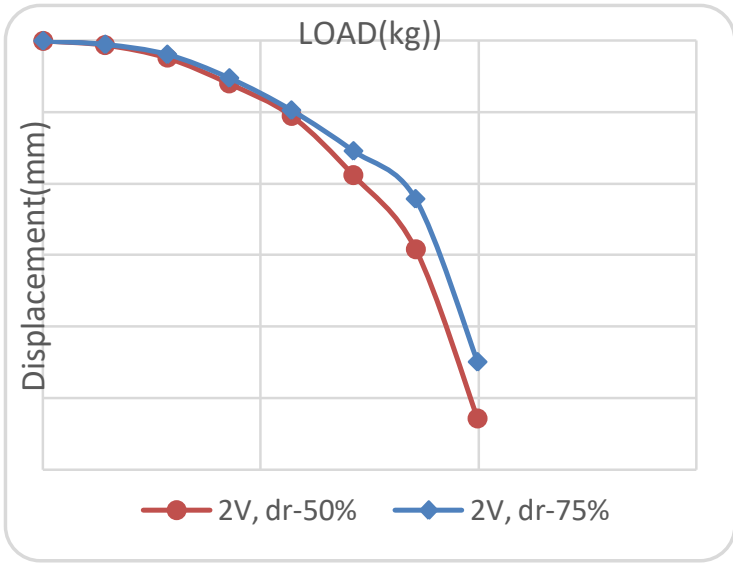

Figure 2: $2 \mathrm{~V}, \mathrm{dr}-50 \% \& 75 \%$

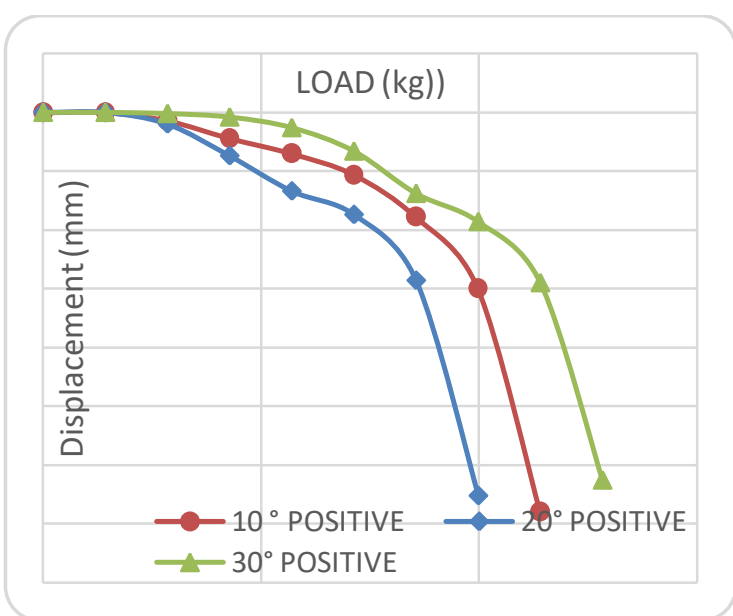

Figure 3: 1V-1B dr-50 \%( positive)

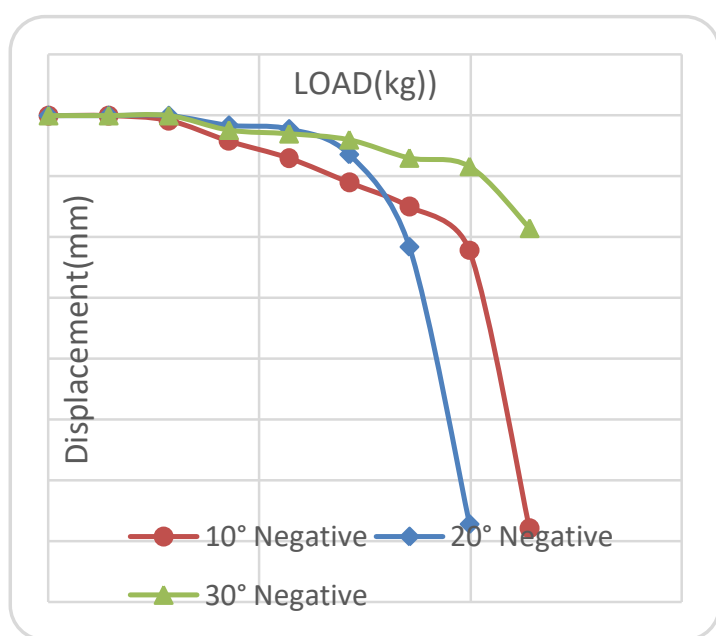

Figure 4: 1V-1B dr-50 \%( negative) 


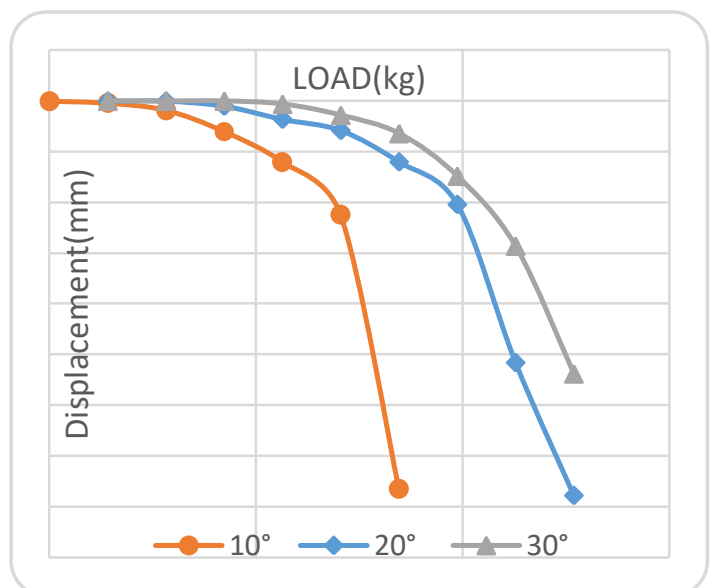

Figure 5: 2V-2B dr-50 \%( Positive and Negative)

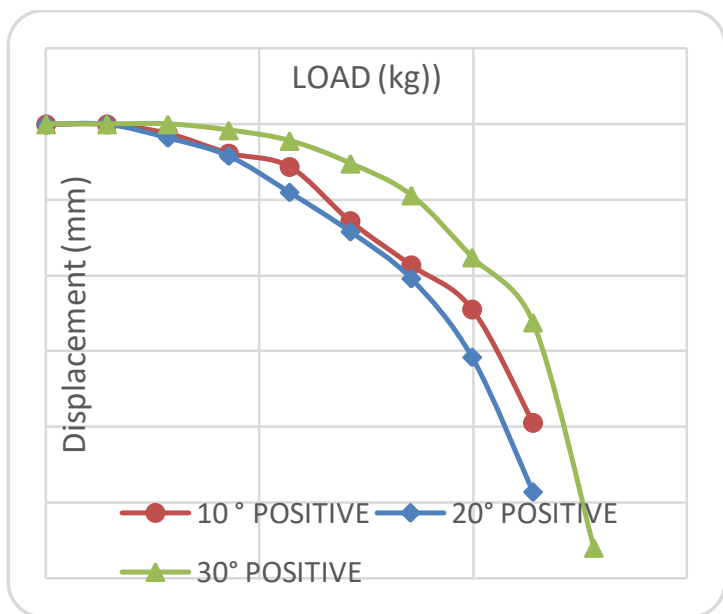

Figure 6: 1V-1B dr-75 \%( Positive)

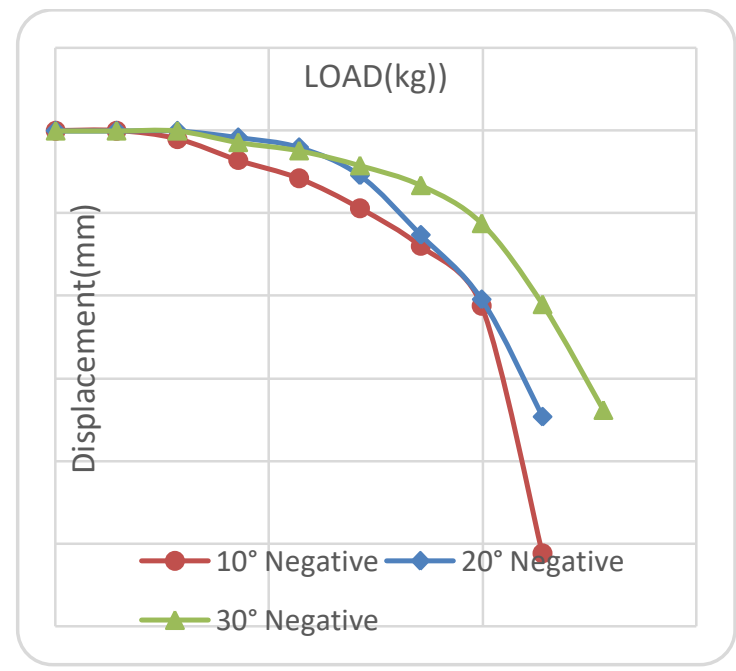

Figure 7: 1V-1B dr-75 \%( Negative)

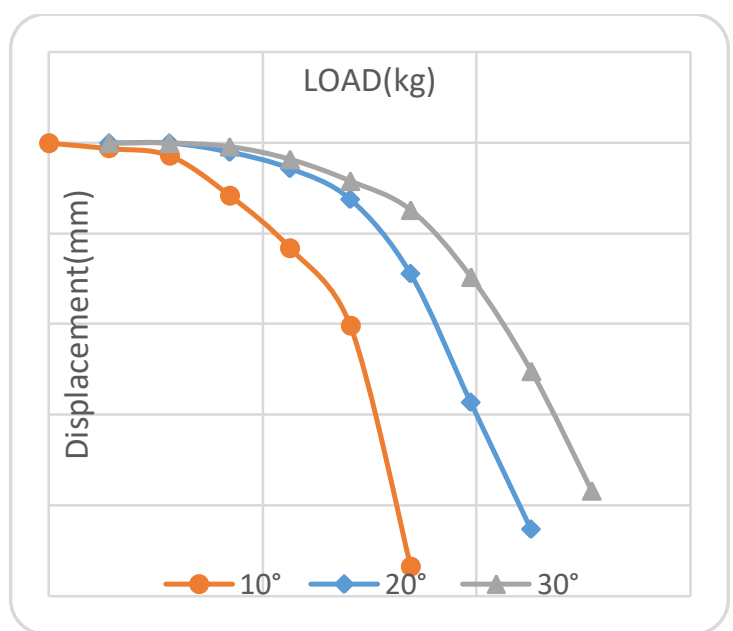

Figure 8: 2V-2B dr-75 \%( Positive and Negative)

The results are related with vertical and batter pile group. The uplift capacity is higher for medium dense sand condition and dense sand condition. The uplift capacity of a single pile and group piles improves significantly with an increase the relative density of soil and batter angle.

\section{CONCLUSION}

The following conclusion is drawn from the presentstudy:

1. From the test result negative batter pile groups gives more capacity compared to positive batter pile groups.

2. Batter pile group $\left(10^{\circ}, 20^{\circ}, 30^{\circ}\right)$ offer more resistance compare to vertical pile group

3. In 4 pile group $30^{\circ}$ angle batter pile offer more resistance compare to $10^{\circ}, 20^{\circ}$ angle piles.

4. Pull-out capacity of a batter pile inmedium dense and dense sand conditions increases with the increase of batter angle attains maximum value.

\section{REFERENCES}

1. K. Shanker, P.K. Basudhar, N.R. Patra, Uplift capacity of pile groups embedded in sand; prediction and performance, Journal of Soils and Foundations 46 (5) (2007) 633-640.

2. Hanna, A. M., Afram, A. 1986. Pullout capacity of single batter piles in sand. Canadian Geotechnical Journal. 23(3):387-392

3. Giannakou A, Gerolymos N, Gazetas G, Tazoh T, AnastasopoulosI.Seismicbehavior of batter piles: Elastic response. Journal of Geotechnical and Geoenvironmental Engineering, 2010, 136(9): 1187-1199

4. Joshi, A.C. (2004). "Compressive loading effects on uplift behaviour of model single piles and pile groups." M.Techthesis, I.I.T. Kanpur, India.

5. Meyerhof, G.G. and Adams, J.I. (1968). The Ultimate Uplift Capacity of Foundations. Can. Geotech. Jour., 5(4), 225-244.

6. Chae D., Cho W. and Hyung-Yoon Na (2012): Uplift capacity of belled pile in weathered sandstones, International Journal of Offshore and Polar Engineering (ISSN 1053-5381) Vol. 22, No. 4,December, pp. 297-305.

7. Bose Kimi K. and Krishnan A. (2009),Pull-out capacity of model piles in sand, IGS Chennai Chapter, Students Paper Competition, pp. 49-54

8. SastryVankamamidi, "Behaviourof Flexible Batter". ICCES, vol.4, no.3, pp.167-170, 2007 
9. Madav Sanatkmarjuvekar

and probhakarjagannathpise"Behaviour of rigid batter piles and pilegroups subjected to horizontal load in sand". Indian geotechnical journal 38(2), 2008, 221-242.

10. Shanker, K., Basudhar, P. K. And Patra N. R.(2006): 'Uplift Capacity of Single Piles Embedded in Sand', IGJ., Vol. 36. No. 4, pp.334-347 